\title{
Ion Formation Mechanism in Laser Desorption Ionization of Individual Nanoparticles
}

\author{
Melissa S. Reinard and Murray V. Johnston \\ Department of Chemistry and Biochemistry, University of Delaware, Newark, Delaware, USA
}

Covariance mapping is used to study ion formation mechanisms in laser desorption ionization of individual 50 or $220 \mathrm{~nm}$ diameter particles having compositions similar to ambient aerosol. Single particle mass spectra are found to vary substantially from particle to particle. This variation is systematic - the energetically preferred ions (e.g., lowest ionization energy, highest electron affinity) are positively correlated with each other and negatively correlated with less preferred ions. For the compositions studied, the average positive ion yield is two to five times greater than the negative ion yield, indicating that free electrons are the main negatively charged species. For many particles, typically $20 \%$ to $40 \%$ of those analyzed, only positive ions are detected. Smaller particles give fewer negative ions, presumably because the plume is less dense and electron capture is less likely. The results suggest that ion formation occurs by a two stage process. In the first stage, photoionization of laser desorbed neutrals gives cations and free electrons. In the second stage, collisions in the plume cause electron capture and competitive charge transfer. When the particle ablates in a manner giving a dense plume with many collisions, the energetically preferred positive and negative ions are dominant. When the particle ablates in a manner giving a less dense plume with fewer collisions, the less preferred ions are able to survive and the energetically preferred ions constitute a lower fraction of the total ion signal. Systematic particle to particle variations of relative signal intensities can complicate ambient particle classification efforts by spreading a single particle composition over several classes. (J Am Soc Mass Spectrom 2008, 19, 389-399) @ 2008 American Society for Mass Spectrometry

$\mathrm{O}$ ver the past decade, single particle mass spectrometry has emerged as a powerful technique to study the chemical properties of atmospheric particles in real-time. While a variety of ionization schemes have been used, single step laser desorption ionization (LDI) is the most common [1-3]. In our laboratory, RSMS uses a single $193 \mathrm{~nm}$ laser pulse to ablate and ionize material from the particle [4]. Intense ion signals can be obtained from most particle compositions: refractory and semivolatile, organic and inorganic. A common feature of this and other laser desorption ionization sequences is that the ionization mechanism is not fully understood [2].

The LDI mass spectra from single particle mass spectrometers are similar to those obtained with laser microprobe mass spectrometry (LAMMS), a decades old method capable of analyzing particles and bulk materials deposited on a substrate [5, 6]. Similar to LAMMS, single particle mass spectrometers also ablate and ionize particles with high-energy laser pulses, but particles are suspended in the center of the source region and analyzed less than a millisecond after entering the vacuum [7].

Some effort has been made to elucidate the mecha-

Address reprint requests to Dr. M. V. Johnston, Department of Chemistry and Biochemistry, University of Delaware, Newark, DE 19716, USA. E-mail: mvj@udel.edu nisms of LDI in single particle mass spectrometry. Measurements of the kinetic energy distribution of ions formed by LDI has provided some information regarding the physical processes that occur during ionization $[8,9]$. Computational models have characterized the disintegration of particles irradiated with a short laser pulse [10-12]. Most studies of the ion formation mechanism in LDI, though, have been performed on solids and substrate mounted samples [13, 14].

It is well known that a significant shot to shot variation exists in the mass spectra obtained by LDI. For this reason, quantification by LDI is generally performed by averaging the signal acquired from many laser shots $[15,16]$. It is not known if this variability is systematic or random, though it is generally assumed to be random. Covariance mapping is a technique which was introduced for use with time-of-flight laser mass spectrometry to compare variations of the signal of different ions over many laser shots and use these variations to elucidate ionization mechanisms [17]. Covariance mapping has been used to study laser ionization of conducting surfaces [18-20], gas-phase species [21, 22], and biomolecular ions produced by MALDI [23], as well as gasoline samples analyzed by GC-MS [24, 25]. We report here the application of covariance mapping to study ion formation from isolated, single nanoparticles. The particle compositions studied are models for common atmospheric aerosols including sodium chloride (sea salt 
aerosol), ammonium sulfate and nitrate (secondary inorganic aerosol), sodium sulfate and ammonium nitrate (transformed sea salt aerosol), and ammonium sulfate/ nitrate with oleic acid (organic aerosol with secondary inorganic components).

\section{Experimental}

The RSMS design is described in detail elsewhere [4]. The instrument has been reconfigured to include a reflectron time-of-flight mass analyzer (Figure 1). This change increases the resolving power of positive ion detection to $\mathrm{m} / \Delta \mathrm{m}=400$ at $\mathrm{m} / \mathrm{z}$ 39. Although the reflectron is set to operate in the positive ion mode only, the instrument can be operated in dual-linear mode as a second multichannel plate detector (Burle Electro-optics, Sturbridge, MA) has been installed behind the reflecting grid of the reflectron mass analyzer. Positive and negative ions are created by laser desorption ionization with a 193 nm ArF excimer laser (GAM Laser, Orlando, FL) that counter-propagates collinearly with the particle beam. The laser beam is focused to give a fluence of $\sim 4 \mathrm{~J} / \mathrm{cm}^{2}$. The source region is approximately $1 / 2 \mathrm{in}$. wide and is surrounded by stainless steel mesh grids that are $1 / 2$ in. in diameter. In the "reflectron" mode of operation, positive ions are analyzed by the reflectron analyzer and negative ions are analyzed by an opposite linear analyzer. In the "linear" mode, the reflectron is grounded, the reflector detector is turned off and the linear detector behind the reflectron is turned on (Figure 1). While the reflectron can be used only for positive ion detection, the linear mode of the reflectron chamber can be used for either polarity of ions. When the reflectron chamber is operated in the linear mode, positive and negative ions are analyzed as shown in Figure 1. The polarities can be reversed ("reverse linear" mode of operation) and negative ions are detected by the detector behind the reflectron, while positive ions are detected through the linear analyzer. Voltages for the various modes used in this study are given in Table 1.

Setting RSMS to run in "linear" and "reverse linear" modes allows for the quantification of transmission efficiencies between the two linear analyzers. For each mode, at least 9700 particles from aerosolized solutions of $\mathrm{NaCl}, \mathrm{NaNO}_{3}$, and a 1:1 $\mathrm{M}$ mixture of $\mathrm{NaCl}$ and $\mathrm{NaNO}_{3}$ were analyzed. Since the particles and laser energy were the same for both modes, the ions produced should also be the same. Thus, the ratio of positive to negative ion signal for each mode allows the relative transmission efficiencies to be determined. Ion signals were obtained from the raw (time domain) spectra.

For covariance mapping, the reflectron mode was used. Single particle spectra were mass calibrated, binned to $\pm 0.5 \mathrm{~m} / \mathrm{z}$ about each integer, integrated, and normalized. Covariance matrices were calculated using MatLab software (MathWorks, Natik, MA). Only those particles producing both positive and negative ion signals were used in the calculations. Art2-a was used to classify some single particle spectra into groups of similar composition. The vigilance parameter was set at 0.5 and the

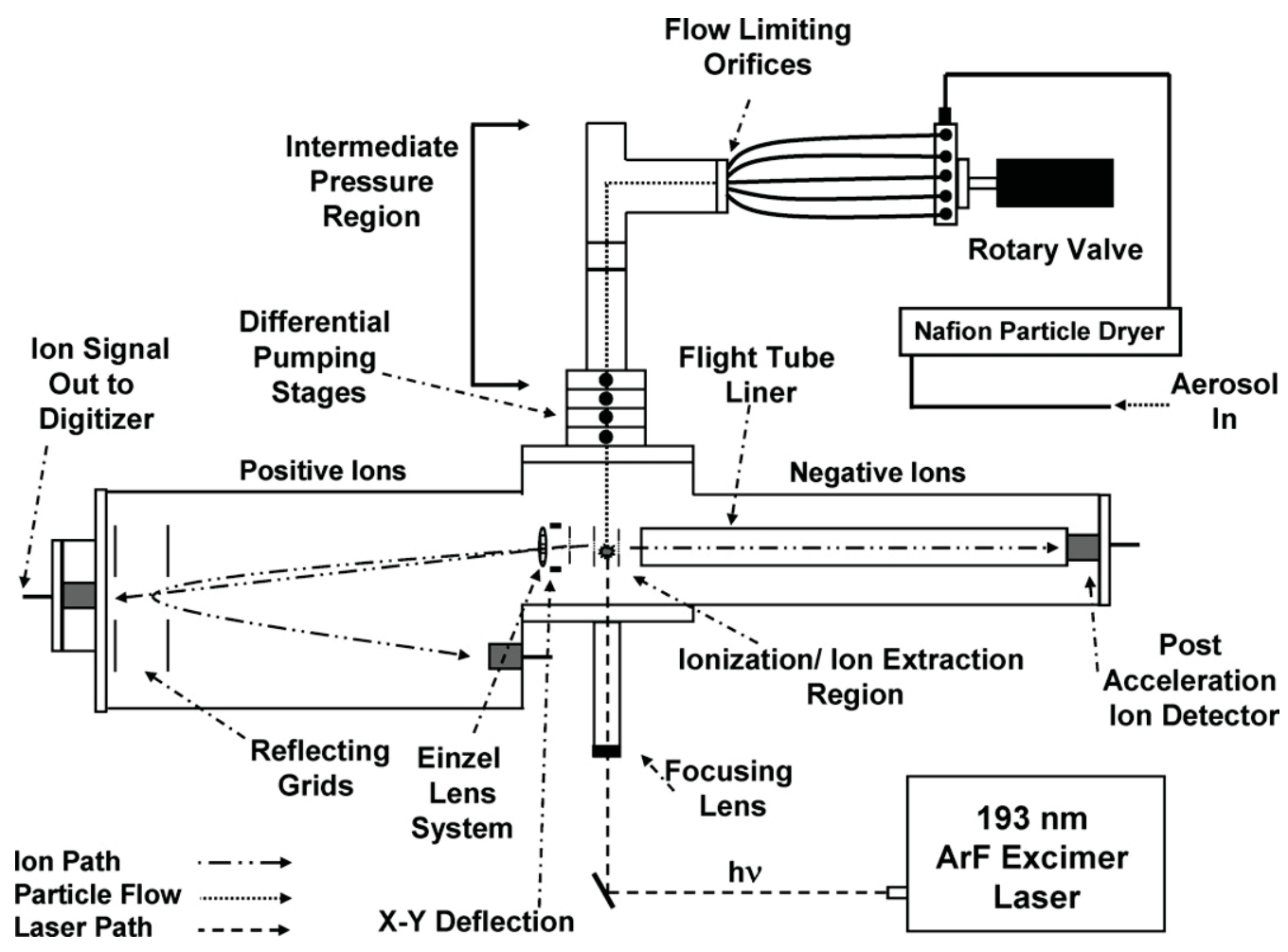

Figure 1. A schematic of the RSMS configuration used in this work. 
Table 1. Voltages for the three modes of operation ${ }^{\mathrm{a}}$

\begin{tabular}{lcccccccccc}
\hline \multicolumn{1}{c}{ Voltages $(k V)$} & VA1 & VA2 & VR1 & VR2 & FOC & VXY & VL & VDR & VDL \\
\hline \hline Reflectron mode & +4.070 & +2.760 & +2.725 & +4.47 & +0.025 & +0.180 & +8.79 & +3 & 0 & +10 \\
Linear mode & +4.070 & +2.760 & 0 & 0 & 0 & 0 & +5 & 0 \\
Reverse Linear mode & -4.070 & -2.760 & 0 & 0 & 0 & 0 & -10 & +10 \\
\hline
\end{tabular}

aVA1, VA2 = voltages applied to the source grids; VR1, VR2 = voltages applied to the reflectron grids; FOC $=$ voltage applied to Einzel Lens; VXY = voltage applied to $x-y$ deflection plates; $V L=$ voltage applied to linear flight tube opposite the reflectron chamber; $V D R=$ voltage applied to reflectron detector; $\mathrm{VDL}_{\text {ref }}=$ voltage applied to linear detector behind the reflectron; $V D L_{\text {lin }}=$ voltage applied to linear detector opposite the reflectron chamber. The flight tube in the reflectron chamber was at ground for all experiments.

learning parameter was set to 0.05 . These values are typically used to classify ambient single particle datasets [26-28].

Particles were generated from a constant output atomizer (model 3076; TSI Inc., St. Paul, MN) with ethanol-water (75:25 vol/vol) solutions of $\mathrm{NaCl}, 1: 1 \mathrm{~mol}$ ratio of ammonium sulfate and ammonium nitrate, $1: 1 \mathrm{~mol}$ ratio of sodium sulfate and ammonium nitrate, and 1:1:1 mol ratio of ammonium sulfate, ammonium nitrate, and oleic acid. The RSMS inlet is able to select particles having vacuum aerodynamic diameters $\left(\mathrm{d}_{\mathrm{va}}\right)$ ranging from $30 \mathrm{~nm}$ to $1.2 \mu \mathrm{m}$ with a $\sigma_{\mathrm{g}}=1.1$ around the selected size $[4,29]$. In most experiments, $220 \mathrm{~nm}$ diameter particles were selected. A few experiments were performed with $50 \mathrm{~nm}$ diameter $\mathrm{NaCl}$ particles.

\section{Results and Discussion}

\section{Relative Ion Yields}

Determination of the relative yield of positive and negative ions requires measurement of the relative transmission efficiencies of the two (linear) mass analyzers. Transmission efficiencies were obtained by measuring the positive and negative ion signal intensities for the two modes of operation, linear and reverse linear. For a given particle composition, size and laser pulse energy, the absolute yield of positive ions, $N+$, is given by:

$$
N+=\mathrm{S}_{1+}\left(\mathrm{R}_{\mathrm{A}}\right)^{-1}=\mathrm{S}_{2+}\left(\mathrm{R}_{\mathrm{B}}\right)^{-1}
$$

where $S_{1+}$ is the total ion signal from the positive ion detector for the "linear" mode (\#1), $\mathrm{R}_{\mathrm{A}}$ is the transmission efficiency for analyzer " $\mathrm{A}$ " (the linear analyzer on the reflectron side of the instrument), $S_{2+}$ is the total ion signal from the positive ion detector for the "reverse linear" mode (\#2), and $R_{B}$ is the transmission efficiency for analyzer " $\mathrm{B}$ " (the linear analyzer opposite the reflectron chamber). Likewise, the yield of negative ions, $\mathrm{N}-$, is:

$$
\mathrm{N}-=\mathrm{S}_{1-}\left(\mathrm{R}_{\mathrm{B}}\right)^{-1}=\mathrm{S}_{2-}\left(\mathrm{R}_{\mathrm{A}}\right)^{-1}
$$

where $S_{1-}$ is the total ion signal from the negative ion detector for mode 1 and $S_{2-}$ is the total ion signal from the negative ion detector for mode 2. Combining eqs 1 and 2 gives the relative transmission efficiency:

$$
\frac{R_{B}}{R_{A}}=\sqrt{\frac{S_{2+} S_{1-}}{S_{1+} S_{2-}}}
$$

The results of this calculation for several particle compositions are listed in Table 2. Only atomic and molecular ions are included in the signal intensity measurements, i.e., free electrons are excluded. Accordingly, particles giving free electrons as the only negative charge carriers are excluded from the analysis. For particles that produce both positive and negative atomic or molecular ions, the relative transmission efficiency is $\sim 1$. The slightly smaller transmission efficiency of linear analyzer " $\mathrm{A}$ " on the reflectron side of the instrument most likely arises from its greater flight tube length $(121 \mathrm{~cm}$ for analyzer " $\mathrm{A}$ " versus $70 \mathrm{~cm}$ for analyzer " $\mathrm{B}$ "). The composition dependence of the relative transmission efficiency may arise from a $\mathrm{m} / \mathrm{z}$ dependence on transmission since the distribution of ions produced from each composition is different (e.g., $\mathrm{NaCl}_{2}{ }^{-}$from $\mathrm{NaCl} ; \mathrm{NO}_{2}{ }^{-}$and $\mathrm{NO}_{3}{ }^{-}$from $\mathrm{NaNO}_{3}$ ).

The relative yield of positive $(N+)$ to negative $(N-)$ atomic/molecular ions is given by:

$$
\frac{\mathrm{N}+}{\mathrm{N}-}=\sqrt{\frac{\mathrm{S}_{1+} \mathrm{S}_{2+}}{\mathrm{S}_{1-} \mathrm{S}_{2-}}}
$$

As shown in Table 2, the positive ion yield is 2 to 5 times greater than the negative ion yield. This bias along with the observation that many particles do not give atomic or molecular negative ions at all indicates that most of the negative charges produced by LDI are free electrons. Unlike substrate mounted samples where photo-

Table 2. Relative transmission efficiencies and yields of positive and negative ions

\begin{tabular}{lrrc}
\hline & $\mathrm{NaCl}$ & $\mathrm{NaNO}_{3}$ & $1: 1 \mathrm{NaCl} / \mathrm{NaNO}_{3}$ \\
\hline \hline $\begin{array}{l}\text { Total number of } \\
\text { particles }\end{array}$ & 19,532 & 19,468 & 21,354 \\
$\begin{array}{l}\text { Number of particles } \\
\text { with +/- }\end{array}$ & 13,162 & 11,974 & 13672 \\
$\mathrm{R}_{\mathrm{B}} / \mathrm{R}_{\mathrm{A}}^{\mathrm{b}}$ & $1.4^{\mathrm{c}}$ & $1.1^{\mathrm{c}}$ & $1.2^{\mathrm{c}}$ \\
$\mathrm{N}+/ \mathrm{N}-$ & $4.9^{\mathrm{c}}$ & $2.4^{\mathrm{c}}$ & $3.7^{\mathrm{c}}$ \\
\hline
\end{tabular}

${ }^{a} d_{\text {va }}=220 \mathrm{~nm}$.

${ }^{b} R_{A}, R_{B}$ are the relative transmission efficiencies of the two linear analyzers; " $A$ " is the analyzer in the reflectron chamber.

c $95 \%$ confidence intervals $\pm 0.9 \%$. 
electrons can be emitted from the substrate [30], an isolated particle passing through the source region is a closed system, that is, the total number of positive and negative charges released into the gas-phase during LDI must be equal. If the particle is only partially ablated, possibly some charge is carried away with the remaining portion of the particle. While partial ablation is possible with micron-size particles, it is unlikely for the particle sizes in this work because the ablation depth for the laser conditions used is on the order of hundreds of nanometers [31]. If we assume that the initial ionization step in LDI is photoionization of an atom, molecule or cluster produced by laser desorption [32], then electrons are the initial negatively charged species and formation of negative atomic and molecular ions require electron capture in the plume. It is unlikely that plasma formation initiates electron/ion formation in an isolated portion of the particle since the laser wavelength and particle size are similar [33]. Furthermore, the laser fluence used is unlikely to induce plasma formation throughout the particle [12]. If not all electrons are captured, then the negative ion yield is smaller than the positive ion yield. Though a bias toward formation of positive atomic and molecular ions was suggested in previous work [34, 35], this is to the authors' knowledge the first time it has been quantified for single particles.

The ion yields in Table 2 are averaged over many particles. Not reflected in this table are the significant particle to particle variations in relative ion yield. In fact, a third of the particles in this experiment gave no negative atomic or molecular ions at all. This variation is illustrated in Table 3, where the vector spectra of three Art2-a classes identified from the 19,532 NaCl particles $\left(\mathrm{d}_{\mathrm{va}}=220 \mathrm{~nm}\right)$ are given. The largest class, Class A, representing $52 \%$ of the particles in the dataset, shows both positive and negative ions. The smallest class, Class B, representing $7 \%$ of the particles, also shows both positive and negative ions but the relative intensities of negative ions are different. In Class $\mathrm{A}$, the cluster ion $\mathrm{NaCl}_{2}{ }^{-}$has a higher relative intensity than other negative ions while in Class $\mathrm{B}$, atomic ion $\mathrm{Cl}^{-}$and molecular ion $\mathrm{NaCl}^{-}$have enhanced signal intensities. The third class, Class C, representing $41 \%$ of the particles, shows very little negative ion intensity. In this case, the Art-2a algorithm cannot distinguish between particles that generate no negative ions and those that generate a very small amount of $\mathrm{NaCl}_{2}{ }^{-}$. Particles having no negative ion signal at all represented $33 \%$ of the particles in the dataset and were included in Class $\mathrm{C}$.

Table 3. Normalized ion signal intensities of three particle classes obtained by Art-2a analysis of $220 \mathrm{~nm} \mathrm{NaCl}$ particles

\begin{tabular}{ccrrrrr}
\hline Class & $\mathrm{Na}^{+}$ & $\mathrm{Na}_{2}{ }^{+}$ & $\mathrm{Na}_{2} \mathrm{Cl}^{+}$ & $\mathrm{Cl}^{-}$ & $\mathrm{NaCl}^{-}$ & $\mathrm{NaCl}_{2}{ }^{-}$ \\
\hline \hline A & $64 \%$ & $1 \%$ & $35 \%$ & $5 \%$ & $0 \%$ & $95 \%$ \\
$B$ & $61 \%$ & $1 \%$ & $38 \%$ & $36 \%$ & $1 \%$ & $63 \%$ \\
$C$ & $64 \%$ & $1 \%$ & $35 \%$ & - & - & - \\
\hline
\end{tabular}

Table 3 highlights the difficulty of classifying particles analyzed by LDI-more than one class can be obtained for a single composition particle. The problem is exacerbated when negative ion spectra are included in the analysis. Indeed, when classification of this dataset is based on the positive ion spectra alone, only a single class is obtained. The large particle to particle variation in negative ion yield is clearly a complicating factor. For this reason, we usually classify ambient particle datasets on the basis of positive ion spectra alone and then assess the distribution of negative ions within these classes [36, 37].

\section{Covariance Mapping}

Particle to particle variations of the relative ion yield are a consequence of the ion formation mechanism in LDI. The mechanism can be probed further by covariance mapping based on the assumption that a correlation in signal intensities of two ions indicates a physical process that links the two ions [19]. The covariance matrix, $\mathrm{C}(\mathrm{x}, \mathrm{y})$, is given by:

$$
C(x, y)=\frac{1}{n} \sum_{j=1}^{n}\left(x_{i}-\bar{x}\right)\left(y_{i}-\bar{y}\right)
$$

where $x_{i}$ and $y_{i}$ represent ion signal intensities at $m / z x$ and $y$, and $\bar{x}$ and $\bar{y}$ represent the mean signal intensity at $m / z x$ and $y$ for all particles. If the covariance of two ions is a positive number, the ions are said to be positively correlated and if the covariance is a negative number, the ions are negatively correlated. When the covariance is zero, the ions have no correlation at all. A normalized covariance matrix, also known as the correlation coefficient, was employed in this work and is given by:

$$
\gamma(x, y)=\frac{C(x, y)}{[C(x, x) C(y, y)]^{1 / 2}}
$$

Since LDI detection efficiencies differ based on composition, e.g., $\mathrm{Na}^{+}$is very easily detected while $\mathrm{NH}_{4}{ }^{+}$is not, this normalization is necessary to compare fluctuations between signals that vary greatly in absolute intensity. Here, a correlation coefficient of 1 indicates a perfect correlation (the two ion signals increase and decrease in intensity together) while -1 indicates a perfect negative correlation (as one signal increases, the other decreases). The statistical significance of the correlation coefficient [38] depends on the number of particles analyzed, though a value significantly different than zero does not necessarily indicate a strong correlation. The value at which the calculated correlation coefficient could not be distinguished from zero ranged from 0.024 to 0.044 , except for ammonium sulfate/nitrate, where the number of particles analyzed was limited and the statistically significant value was 0.21. When interpreting the results, we define strong 
Table 4. Frequency of detection ${ }^{\mathrm{a}}$ and average normalized signal ${ }^{\mathrm{b}}$ for positive and negative ions from 50 and $220 \mathrm{~nm}\left(\mathrm{~d}_{\mathrm{va}}\right) \mathrm{NaCl}$ particles

\begin{tabular}{|c|c|c|c|c|c|c|}
\hline Ion detected & $\mathrm{Na}^{+}$ & $\mathrm{Na}_{2}{ }^{+}$ & $\mathrm{Na}_{2} \mathrm{Cl}^{+}$ & $\mathrm{Cl}^{-}$ & $\mathrm{NaCl}^{-}$ & $\mathrm{Na}_{2} \mathrm{Cl}^{-}$ \\
\hline $50 \mathrm{~nm}(\text { all })^{\mathrm{c}, \mathrm{e}}$ & $100 \%$ & $22 \%$ & $80 \%$ & $12 \%$ & $3 \%$ & $30 \%$ \\
\hline $220 \mathrm{~nm}(\text { all })^{\mathrm{c}, \mathrm{e}}$ & $100 \%$ & $51 \%$ & $100 \%$ & $25 \%$ & $5 \%$ & $78 \%$ \\
\hline $50 \mathrm{~nm}( \pm \text { ions })^{\mathrm{d}, \mathrm{f}}$ & $100 \%$ & $32 \%$ & $99 \%$ & $41 \%$ & $10 \%$ & $98 \%$ \\
\hline $220 \mathrm{~nm}( \pm \text { ions })^{\mathrm{d}, \mathrm{e}}$ & $100 \%$ & $55 \%$ & $100 \%$ & $32 \%$ & $7 \%$ & $99 \%$ \\
\hline Average Signal, $50 \mathrm{~nm}( \pm \text { ions })^{\mathrm{d}, \mathrm{f}}$ & $82 \%$ & $0 \%$ & $18 \%$ & $7 \%$ & $0 \%$ & $93 \%$ \\
\hline Average Signal, $220 \mathrm{~nm}( \pm \text { ions })^{\mathrm{d}, \mathrm{e}}$ & $71 \%$ & $0 \%$ & $29 \%$ & $3 \%$ & $0 \%$ & $97 \%$ \\
\hline
\end{tabular}

aPercentage of particles analyzed that gave a nonzero signal for a given ion.

blon signals normalized to the total positive or negative signal intensity.

cData for all particles analyzed.

dData for only those particles which generated both positive and negative ions.

e $95 \%$ confidence intervals are $\pm 1 \%$.

${ }^{\mathrm{f}} 95 \%$ confidence intervals are $\pm 2 \%$.

correlations as $>0.1$ or $<-0.1$ except for ammonium sulfate/nitrate, weak correlations as significantly different from zero, and noncorrelations as statistically indistinguishable from zero.

For covariance mapping, the reflector mode of operation was used to obtain single particle spectra from aerosols generated from four different solutions: sodium chloride, 1:1 mol ratio of ammonium sulfate and ammonium nitrate, 1:1 mol ratio of sodium sulfate and ammonium nitrate, 1:1:1 mol ratio of ammonium sulfate, ammonium nitrate and oleic acid. Table 4 shows the relative ion signal intensities from aerosols generated from the last three solutions. These values are averaged over all single particle mass spectra giving both positive and negative ions. The $\mathrm{NaCl}$ spectra were similar to those in Table 2 . The $\mathrm{NaCl}$ aerosol was characterized at two sizes, 220 and $50 \mathrm{~nm}$, while the other aerosols were only characterized at $220 \mathrm{~nm}\left(\mathrm{~d}_{\mathrm{va}}\right)$. Covariance matrices are illustrated in Figures 2, 3, 4, 5, and 6. In these figures, white areas indicate ion pairs that exhibit a strong positive correlation, light grey areas indicate a significant (but not strong) positive correlation, black areas indicate a strong negative correlation, and dark grey areas indicate a significant (but not strong) negative correlation. Areas that are grey with white hash marks indicate correlation coefficients indistinguishable from zero.

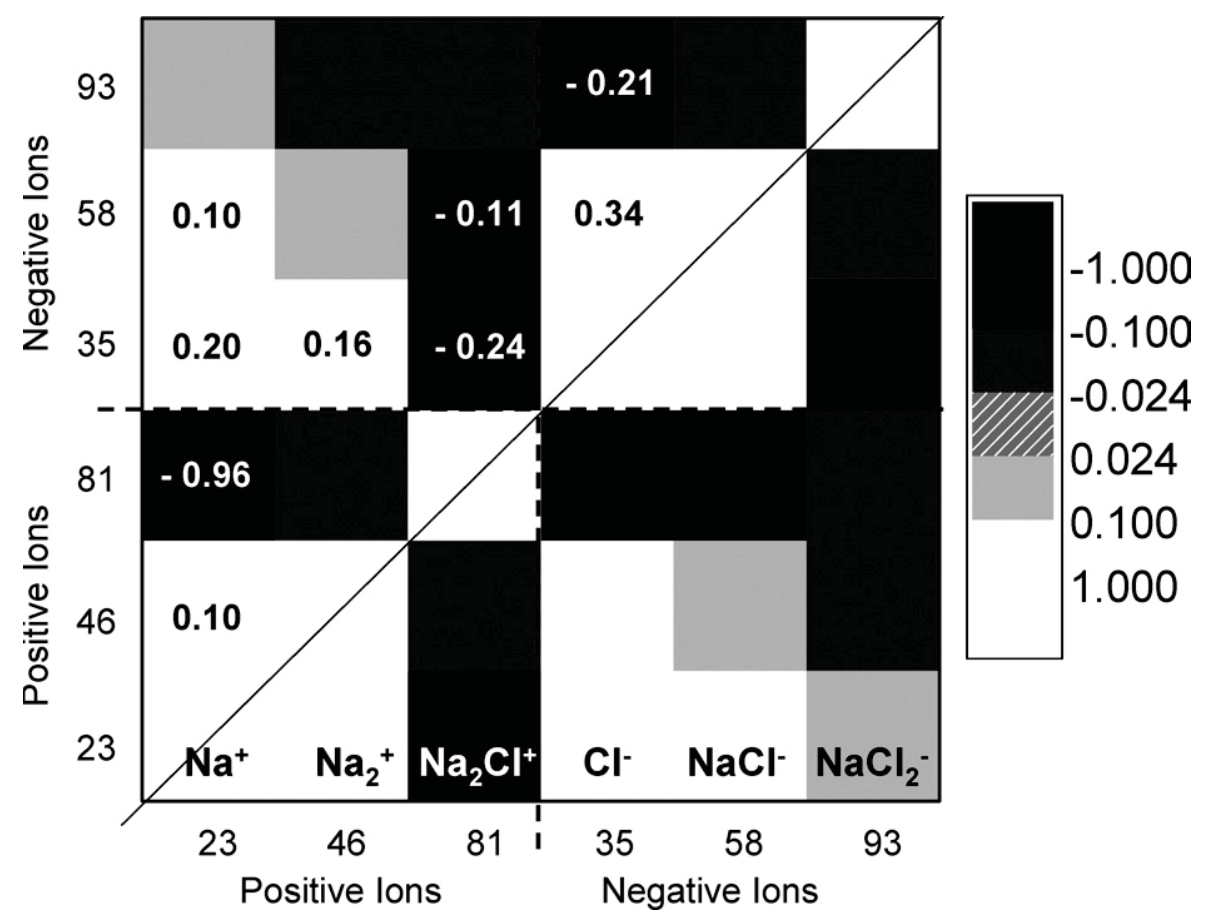

Figure 2. Covariance matrix for $220 \mathrm{~nm} \mathrm{NaCl}$ particles. Black indicates a strong negative correlation, dark grey indicates a nonzero negative correlation, white indicates a strong positive correlation, light grey indicates a nonzero positive correlation, and grey with white hash indicates a correlation indistinguishable from zero ( $95 \%$ confidence level). Correlation coefficients for strong correlations are also given. 


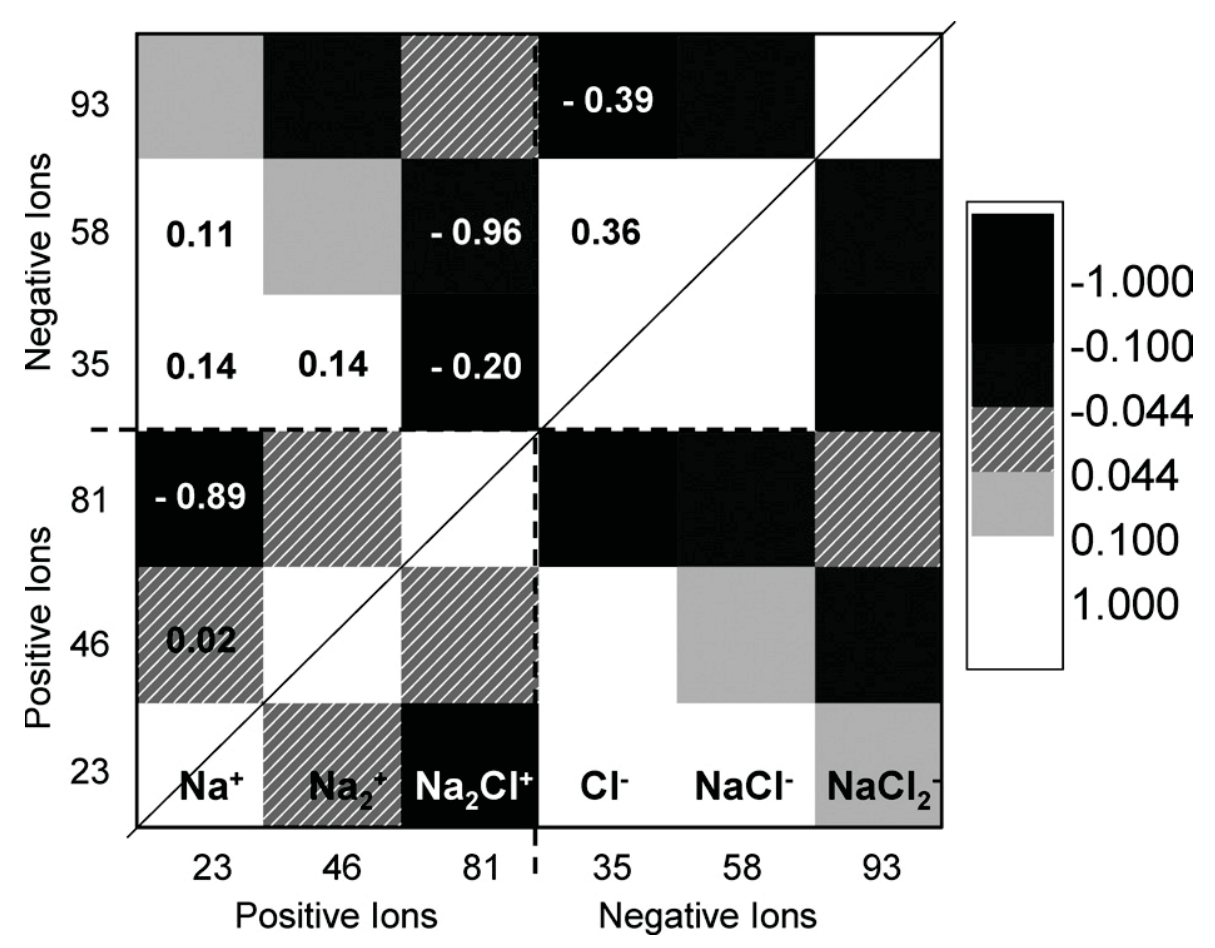

Figure 3. Covariance matrix for $50 \mathrm{~nm} \mathrm{NaCl}$ particles.

Sodium chloride. Figure 2 shows the covariance matrix for $220 \mathrm{~nm} \mathrm{NaCl}$ particles. A total of 14,431 particles were analyzed at $220 \mathrm{~nm}$, and of these the 11,414 particles giving both positive and negative ions $(79 \%$ of total particles) were used to calculate the covariance matrix. Ions included in the map are $\mathrm{Na}^{+}, \mathrm{Na}_{2}{ }^{+}$, and $\mathrm{Na}_{2}{ }^{35} \mathrm{Cl}^{+},{ }^{35} \mathrm{Cl}^{-}, \mathrm{Na}^{35} \mathrm{Cl}^{-}$, and $\mathrm{Na}^{35} \mathrm{Cl}_{2}{ }^{-}$. Positive correlations among the ion pairs $\mathrm{Na}^{+} / \mathrm{Cl}^{-}, \mathrm{Na}^{+} / \mathrm{NaCl}^{-}$, and $\mathrm{Cl}^{-} / \mathrm{NaCl}^{-}$are consistent with a sequence of events in which the particle initially disintegrates into atomic/ molecular cations and free electrons. Ionization could occur either by photoionization of neutrals or plasma formation, although plasma formation is less likely for the laser fluence used in this study [12]. In either case, the electrons are subsequently captured by other atoms/clusters in the plume to give negative ions:

$$
\begin{aligned}
& (\mathrm{NaCl})_{\mathrm{n}} \rightarrow \mathrm{Na}^{+} \mathrm{Cl}+\mathrm{e}^{-}+(\mathrm{NaCl})_{\mathrm{n}-1} \\
& \mathrm{Cl}+\mathrm{e}^{-} \rightarrow \mathrm{Cl}^{-} \\
& \mathrm{NaCl}+\mathrm{e}^{-} \rightarrow \mathrm{NaCl}^{-}
\end{aligned}
$$

The negative ions in eqs 8 and 9 are positively correlated with $\mathrm{Na}^{+}$because the electron produced in eq 7 is required for negative ion formation. An alternative explanation for the positive correlation between $\mathrm{Na}^{+}$ and $\mathrm{Cl}^{-}$is direct dissociation of $\mathrm{NaCl}$ into these ions. This process is considered less likely than dissociation into the neutral atoms because Coulombic attraction between the products increases the activation energy.
Furthermore, simultaneous formation of positive and negative atomic ions is inconsistent with the observation that many particles give positive ions only.

In addition to the above positive correlations, negative correlations among other ion pairs, i.e., $\mathrm{Na}^{+} /$ $\mathrm{Na}_{2} \mathrm{Cl}^{+}, \mathrm{Cl}^{-} / \mathrm{NaCl}_{2}{ }^{-}$, and $\mathrm{Cl}^{-} / \mathrm{Na}_{2} \mathrm{Cl}^{+}$, indicate that cluster ions are formed at the expense of atomic ions through secondary collisions:

$$
\begin{aligned}
& \mathrm{NaCl}+\mathrm{Na}^{+} \rightarrow \mathrm{Na}_{2} \mathrm{Cl}^{+} \\
& \mathrm{NaCl}+\mathrm{Cl} \rightarrow \mathrm{NaCl}_{2} \\
& \mathrm{NaCl}^{-}+\mathrm{Cl} \rightarrow \mathrm{NaCl}_{2}^{-}
\end{aligned}
$$

The smaller positive correlation between $\mathrm{Na}_{2} \mathrm{Cl}^{+}$and $\mathrm{NaCl}_{2}{ }^{-}$most likely reflects two opposing factors: both ions require the same precursor (positive correlation) but compete for reaction with that precursor (negative correlation). The positive correlation of $\mathrm{Na}_{2}{ }^{+} / \mathrm{Na}^{+}$suggests that $\mathrm{Na}_{2}{ }^{+}$is also formed by ionization of a cluster (eq 7) in a manner that does not compete with $\mathrm{Na}^{+}$ formation.

Particle to particle variations in the relative ion yield discussed in the previous section can be understood within the context of a two-stage ion formation process. In the first stage represented by eq 7 , cations and electrons are produced. In the second stage represented by eqs $8-12$, the distribution of charged species evolves through collisions in the plume that lead to electron capture (eqs 8,9) and clustering/charge-transfer (eqs $10-12)$. The final distribution of ions depends on plume 
density and dynamics. If the plume is dispersed, collisional cooling is inefficient, electron capture is unfavorable and hardly any atomic/molecular negative ions are formed. If the plume is dense, collisional cooling is efficient, electrons are efficiently captured, and there is a bias toward cluster formation through subsequent collisions. Intermediate between these two extremes is the situation where collisional cooling permits formation of negative ions, but the bias is away from cluster ions and toward atomic ions. When ablated, each particle produces a different plume density, causing a systematic (not random) variation in the mass spectrum.

The experiment was repeated for $50 \mathrm{~nm} \mathrm{NaCl}$ particles, and out of the 10,552 particle mass spectra obtained, only 3413 gave both positive and negative ion spectra (32\%), a much smaller fraction than for $220 \mathrm{~nm}$ particles. A lower tendency of smaller particles to produce negative ions has been noted previously [34]. Table 4 gives the fraction of particles in the 50 and 220 $\mathrm{nm}$ datasets that give a measurable signal for each of the positive and negative ions discussed above. Also given is the fraction of the total signal intensity that each ion represents. The table shows that cluster ions $\mathrm{Na}_{2} \mathrm{Cl}^{+}$and $\mathrm{NaCl}_{2}{ }^{-}$are detected in a smaller fraction of the particles at $50 \mathrm{~nm}$ than $220 \mathrm{~nm}$, and their contributions to the total signal intensity of each ion polarity are also smaller at $50 \mathrm{~nm}$ than $220 \mathrm{~nm}$. The lower tendency of $50 \mathrm{~nm}$ particles to give negative ions overall and cluster ions in particular are a consequence of plume dynamics. The $50 \mathrm{~nm}$ particles have a larger surface to volume ratio than $220 \mathrm{~nm}$ particles and would be expected to give a less dense plume when ablated. As a result, electron capture and cluster formation (eqs 8-12) are less likely for $50 \mathrm{~nm}$ particles than $220 \mathrm{~nm}$ particles.

The covariance matrix for the 3413 particles giving both positive and negative ions is shown in Figure 3. The correlations in Figures 2 and 3 are remarkably similar suggesting that the reactions leading to ion formation are the same. The only significant difference is the loss of a strong correlation between $\mathrm{Na}^{+}$and $\mathrm{Na}_{2}{ }^{+}$for the $50 \mathrm{~nm}$ particles, which may arise from the lower probability for cluster formation at this particle size.

Ammonium sulfate-ammonium nitrate. For the aerosol generated from a solution of a 1:1 mol ratio of ammonium sulfate and nitrate, 10,434 single particle spectra were obtained $\left(\mathrm{d}_{\mathrm{va}}=220 \mathrm{~nm}\right)$ and of these 140 particles gave both positive and negative ions. The normalized ion signal intensities averaged over all particles giving both positive and negative ions are given in Table 5, Aerosol A. The small fraction of particles giving both positive and negative ions $(\sim 1 \%)$ indicates that electron capture is very inefficient in the plume. The covariance matrix for these 140 particles is shown in Figure 4. Since few particles were included in the calculation, the correlation coefficient required an absolute value greater than 0.21 to be significantly different from zero.

Correlation coefficients are shown in Figure 4 for a variety of positive $\left(\mathrm{H}^{+}, \mathrm{NH}_{4}{ }^{+}, \mathrm{NO}^{+}\right)$and negative $\left(\mathrm{NO}_{2}{ }^{-}, \mathrm{NO}_{3}{ }^{-}, \mathrm{HSO}_{4}{ }^{-}\right)$ions. In addition, $\mathrm{O}^{-}$and $\mathrm{OH}^{-}$ were included in the covariance analysis, but they were omitted from the figure because no significant correlations were found. The covariance matrix for ammonium sulfate/nitrate particles is interpreted within the context of the same two-stage process considered for $\mathrm{NaCl}$ : an initial ionization step to produce cations and electrons, followed by electron capture and/or chargetransfer in the plume. However, unlike $\mathrm{NaCl}$, particles containing ammonium sulfate and nitrate are more likely to disintegrate into stable molecules such as $\mathrm{HNO}_{3}, \mathrm{H}_{2} \mathrm{SO}_{4}, \mathrm{NH}_{3}$, and $\mathrm{NO}_{\mathrm{x}}$ when ablated, which are the species that subsequently undergo ionization. The strong negative correlations of the ion pairs $\mathrm{NO}^{+} / \mathrm{H}^{+}$ and $\mathrm{NO}^{+} / \mathrm{NH}_{4}{ }^{+}$indicate that these ions are undergo competitive charge-transfer in the plume. Among the molecules listed above, NO has the lowest ionization energy. Therefore, if collisions in the plume are extensive, $\mathrm{NO}^{+}$is the energetically favored product:

$$
\begin{aligned}
& \mathrm{M}^{+}+\mathrm{NO} \rightarrow \mathrm{M}+\mathrm{NO}^{+} \\
& \left(\mathrm{M}=\mathrm{HNO}_{3}, \mathrm{H}_{2} \mathrm{SO}_{4}, \mathrm{NH}_{3}, \mathrm{NO}_{\mathrm{x}}, \mathrm{H}\right)
\end{aligned}
$$

Note that $\mathrm{NH}_{4}{ }^{+}$can only be produced from ionized precursors containing $\mathrm{H}$. Each of these species is likely to transfer charge to $\mathrm{NO}$ by the above reaction, effectively cutting off formation of $\mathrm{NH}_{4}{ }^{+}$. A bias toward formation of the lowest ionization energy species has been noted Reilly et al. [39], who found that chargetransfer to lower ionization energy atoms such as alkali/transition metals caused signal suppression of organic material in sediment samples undergoing laser desorption ionization.

The strong negative correlation of $\mathrm{HSO}_{4}{ }^{-}$with $\mathrm{NO}_{2}{ }^{-}$ and $\mathrm{NO}_{3}{ }^{-}$indicate a similar competitive charge-transfer process in the plume:

Table 5. Normalized ion signal intensities of the average of all single particle mass spectra exhibiting both positive and negative ions $\left(\mathrm{d}_{\mathrm{va}}=220 \mathrm{~nm}\right)$

\begin{tabular}{ccrrrrrrrrrrrr}
\hline Solution $^{2}$ & $\mathrm{H}^{+}$ & $\mathrm{NH}_{4}^{+}$ & $\mathrm{Na}^{+}$ & $\mathrm{C}_{2} \mathrm{H}_{3}^{+}$ & $\mathrm{NO}^{+}$ & $\mathrm{C}_{4} \mathrm{H}_{7}^{+}$ & $\mathrm{Na}_{2} \mathrm{O}^{+}$ & $\mathrm{O}^{-}$ & $\mathrm{OH}^{-}$ & $\mathrm{NO}_{2}^{-}$ & $\mathrm{NO}_{3}^{-}$ & $\mathrm{SO}_{3}^{-}$ & $\mathrm{HSO}_{4}^{-}$ \\
\hline \hline $\mathrm{A}$ & $1 \%$ & $2 \%$ & $0 \%$ & $0 \%$ & $97 \%$ & $0 \%$ & $0 \%$ & $0 \%$ & $0 \%$ & $41 \%$ & $4 \%$ & $0 \%$ & $55 \%$ \\
$\mathrm{~B}$ & $1 \%$ & $0 \%$ & $88 \%$ & $0 \%$ & $3 \%$ & $0 \%$ & $8 \%$ & $4 \%$ & $1 \%$ & $44 \%$ & $0 \%$ & $3 \%$ & $48 \%$ \\
$\mathrm{C}$ & $1 \%$ & $20 \%$ & $0 \%$ & $8 \%$ & $25 \%$ & $46 \%$ & $0 \%$ & $0 \%$ & $1 \%$ & $78 \%$ & $18 \%$ & $0 \%$ & $3 \%$ \\
\hline
\end{tabular}

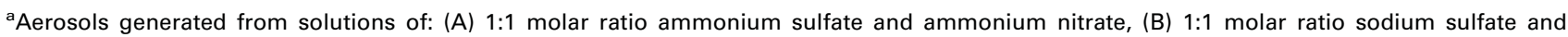
ammonium nitrate, and (C) 1:1:1 molar ratio ammonium sulfate, ammonium nitrate and oleic acid. 


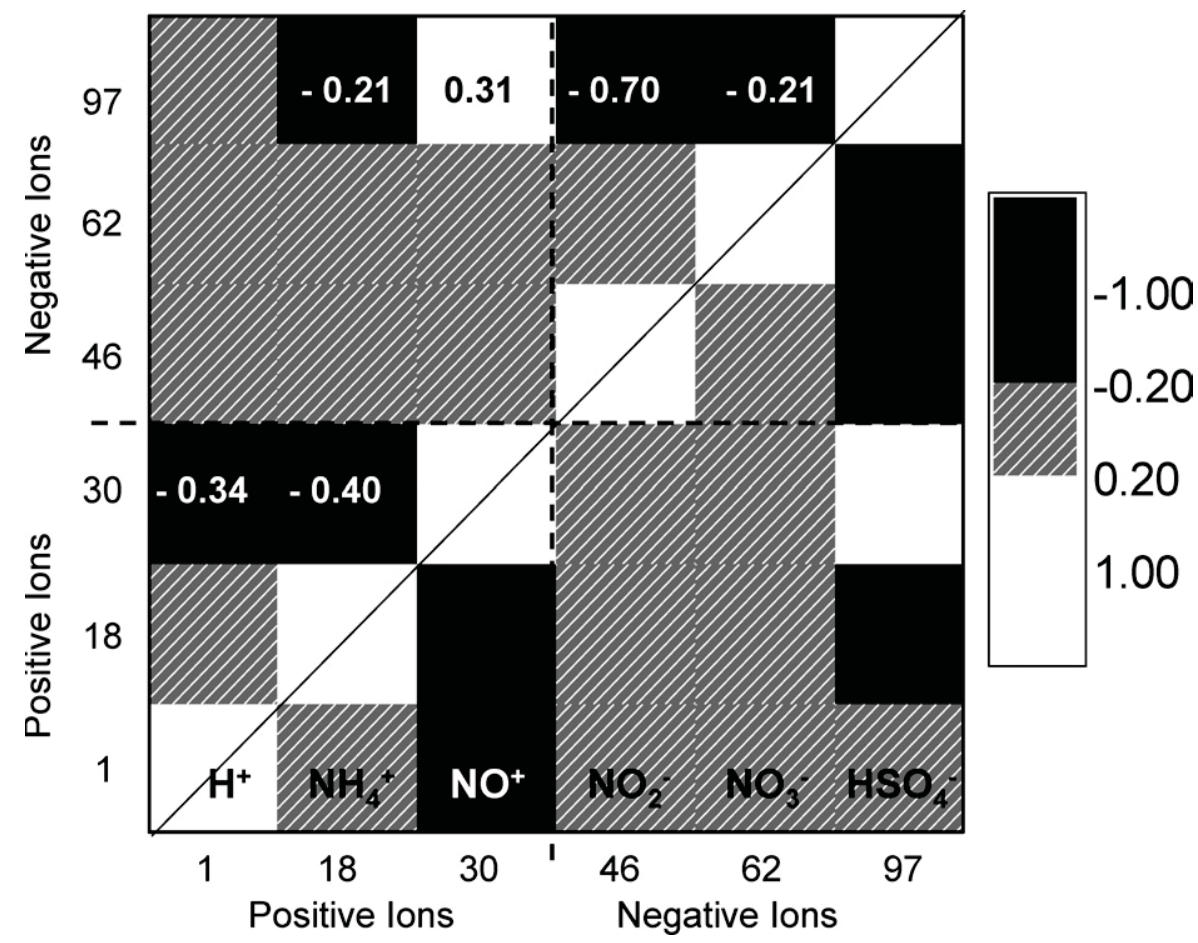

Figure 4. Covariance matrix for $220 \mathrm{~nm}$ particles generated from a solution containing a 1:1 mol ratio of ammonium sulfate and ammonium nitrate.

$$
\mathrm{NO}_{\mathrm{x}}^{-}+\mathrm{H}_{2} \mathrm{SO}_{4} \rightarrow \mathrm{HNO}_{\mathrm{x}}+\mathrm{HSO}_{4}^{-}
$$

Equation 14 is supported by studies of gas-phase clusters containing $\mathrm{HNO}_{3}, \mathrm{H}_{2} \mathrm{SO}_{4}, \mathrm{NO}_{3}{ }^{-}$, and $\mathrm{HSO}_{4}{ }^{-}$that show $\mathrm{HSO}_{4}{ }^{-}$as the predominant product [40]. Furthermore, $\mathrm{HSO}_{4}$ has the highest electron affinity among these species. Thus, $\mathrm{HSO}_{4}{ }^{-}$is energetically preferred if collisions/clustering in the plume are extensive.

The strong positive correlation between $\mathrm{NO}^{+}$and $\mathrm{HSO}_{4}{ }^{-}$is consistent with the above interpretations. When the plume density is high and many collisions occur, $\mathrm{NO}^{+}$and $\mathrm{HSO}_{4}{ }^{-}$are the preferred products. When the plume density is lower, other less energetically favorable ions may survive, and the $\mathrm{NO}^{+}$and $\mathrm{HSO}_{4}{ }^{-}$signal intensities represent a smaller fraction of the total ion signal. Thus, $\mathrm{NO}^{+}$and $\mathrm{HSO}_{4}{ }^{-}$are positively correlated and the particle to particle variation of their signal intensities is systematic, not random.

Sodium sulfate-ammonium nitrate. For the aerosol generated from a solution of a 1:1 mol ratio of sodium sulfate and ammonium nitrate, a total of 10,864 mass spectra $\left(\mathrm{d}_{\mathrm{va}}=220 \mathrm{~nm}\right)$ were obtained. Of these, 6226 particles gave both positive and negative ions (57\%), which were used to generate the covariance matrix. The normalized ion signal intensities averaged over all particles giving both positive and negative ions are given in Table 5, Aerosol B. The covariance matrix in Figure 5 includes a variety of positive $\left(\mathrm{H}^{+}, \mathrm{Na}^{+}, \mathrm{NO}^{+}\right.$, $\left.\mathrm{Na}_{2} \mathrm{O}^{+}\right)$and negative $\left(\mathrm{O}^{-}, \mathrm{OH}^{-}, \mathrm{NO}_{2}{ }^{-}, \mathrm{SO}_{3}{ }^{-}, \mathrm{SO}_{4}{ }^{-}\right.$, $\mathrm{HSO}_{4}{ }^{-}$) ions. Omitted from this figure are $\mathrm{NH}_{4}{ }^{+}, \mathrm{S}^{+}$, and $\mathrm{NO}_{3}{ }^{-}$because no significant correlations were found. For this analysis, correlation coefficients with absolute values greater than 0.031 were significantly different from zero.

Similar to the ammonium sulfate/nitrate particles described above, these particles also disintegrate to give stable molecules such as $\mathrm{HNO}_{3}, \mathrm{H}_{2} \mathrm{SO}_{4}, \mathrm{NH}_{3}$, and $\mathrm{NO}_{\mathrm{x}}$. However, Na atoms are also produced, which may photoionize and/or participate in charge-transfer reactions in the plume. The strong negative correlation between $\mathrm{Na}^{+}$and $\mathrm{NO}^{+}$indicates that $\mathrm{Na}^{+}$is now the energetically favored species rather than $\mathrm{NO}^{+}$owing to competitive charge-transfer in the plume:

$$
\mathrm{NO}^{+}+\mathrm{Na} \rightarrow \mathrm{Na}^{+} \mathrm{NO}
$$

This negative correlation is not surprising given the lower ionization energy of $\mathrm{Na}$, and it is consistent with the negative correlation between $\mathrm{Na}^{+}$and $\mathrm{H}^{+}$. Since $\mathrm{HSO}_{4}^{-}$is still the preferred negative ion ( $\mathrm{HSO}_{4}{ }^{-}$is negatively correlated with $\mathrm{NO}_{2}{ }^{-}$), it is not surprising that $\mathrm{Na}^{+}$and $\mathrm{HSO}_{4}{ }^{-}$are positively correlated. When charge-transfer in the plume is extensive, the formation of both ions is favored; when chargetransfer is limited, other less energetically favored ions such as $\mathrm{NO}^{+}$and $\mathrm{NO}_{2}{ }^{-}$represent greater fractions of the ion current. The preference of $\mathrm{Na}^{+}$over $\mathrm{NO}^{+}$is also indicated by other correlations that have changed relative to ammonium sulfate/nitrate: $\mathrm{NO}^{+}$ is now negatively correlated with $\mathrm{HSO}_{4}{ }^{-}$and positively correlated with $\mathrm{NO}_{2}^{-}$. 


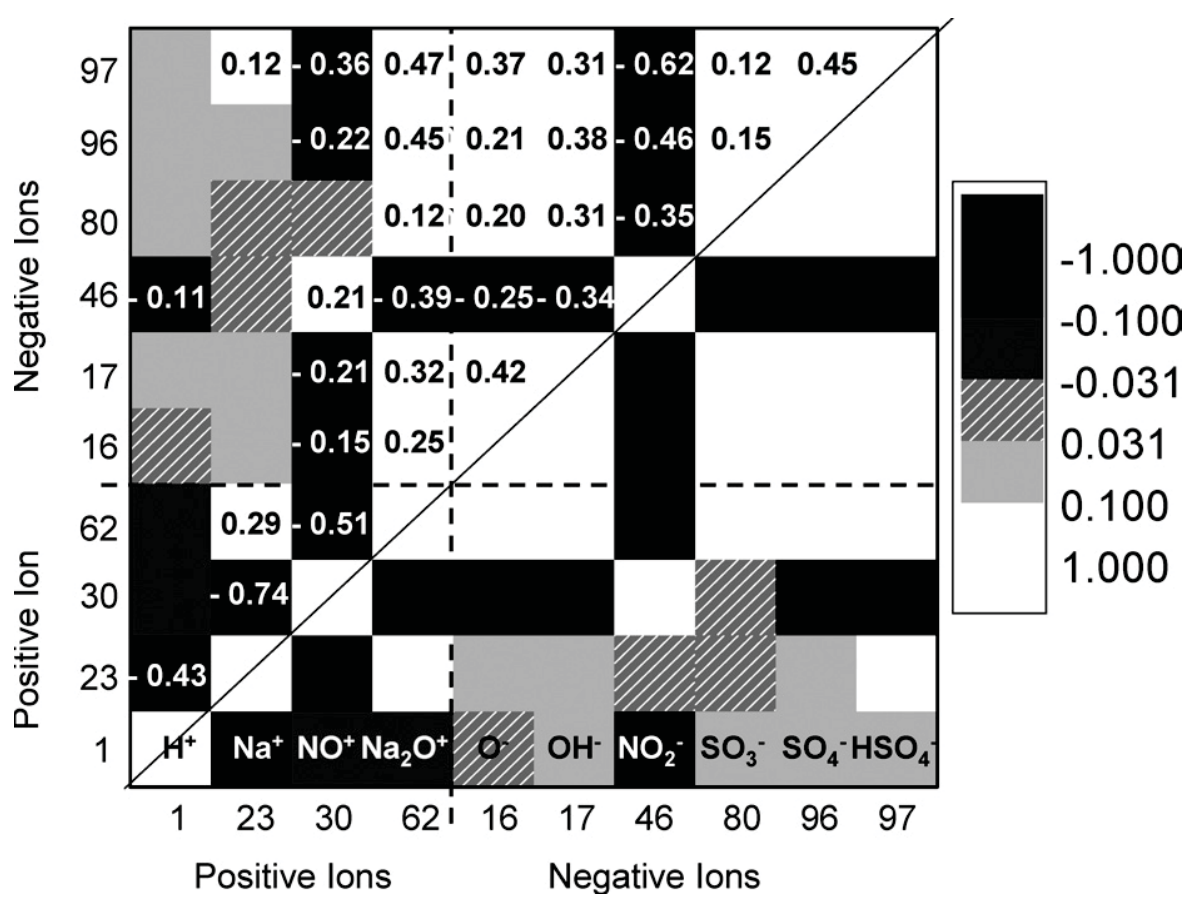

Figure 5. Covariance matrix for $220 \mathrm{~nm}$ particles generated from a solution containing a 1:1 mol ratio of sodium sulfate and ammonium nitrate.

The positive correlations of several ion pairs $\left(\mathrm{O}^{-} /\right.$ $\mathrm{OH}^{-}, \mathrm{O}(\mathrm{H})^{-} / \mathrm{SO}_{3}{ }^{-}, \mathrm{HSO}_{4}{ }^{-} / \mathrm{O}(\mathrm{H})^{-}, \mathrm{HSO}_{4}{ }^{-} / \mathrm{SO}_{3}{ }^{-}$, $\mathrm{HSO}_{4}{ }^{-} / \mathrm{SO}_{4}{ }^{-}$) and the negative correlations of others $\left(\mathrm{NO}^{+} / \mathrm{O}(\mathrm{H})^{-}, \mathrm{NO}_{2}{ }^{-} / \mathrm{O}(\mathrm{H})^{-}, \mathrm{NO}_{2}{ }^{-} / \mathrm{SO}_{3}{ }^{-}, \mathrm{NO}_{2}{ }^{-} / \mathrm{SO}_{4}{ }^{-}\right)$ indicate that the formation of $\mathrm{HSO}_{4}{ }^{-}, \mathrm{O}^{-}, \mathrm{OH}^{-}, \mathrm{SO}_{3}{ }^{-}$, and $\mathrm{SO}_{4}{ }^{-}$are noncompetitive, perhaps through the fragmentation of $\mathrm{HSO}_{4}{ }^{-}$. Analogous to $\mathrm{NaCl}$, the positive correlation between $\mathrm{Na}^{+}$and $\mathrm{Na}_{2} \mathrm{O}^{+}$in this system indicates a similar formation mechanism, probably through clusters.

Ammonium sulfate-ammonium nitrate-oleic acid. For the aerosol generated from a solution of a 1:1:1 mol ratio of ammonium sulfate, ammonium nitrate, and oleic acid, 10,622 single particle spectra were obtained; of these 7070 contained both positive and negative ion signals (67\%). Of the remaining particles, 23 gave positive ions alone, while a much larger number, 3523, gave negative ions alone. This is the only composition studied that gave exclusively negative ions. This situation is rare, for example, in ambient measurements typically less than $0.01 \%$ of the particles analyzed give only negative ions (e.g., reference [27]). We interpret this situation as arising from particles that give mostly $\mathrm{H}^{+}$ions that have large radial kinetic energies such that they are not efficiently transmitted through the mass analyzer. The normalized ion signal intensities averaged over all particles giving both positive and negative ions are given in Table 5, Aerosol C. Figure 6 shows the covariance matrix for several ions: $\mathrm{H}^{+}, \mathrm{NH}_{4}{ }^{+}, \mathrm{C}_{2} \mathrm{H}_{3}{ }^{+}, \mathrm{NO}^{+}$, $\mathrm{C}_{3} \mathrm{H}_{4} \mathrm{O}^{+}$(or $\mathrm{C}_{4} \mathrm{H}_{8}{ }^{+}$), $\mathrm{OH}^{-}, \mathrm{NO}_{2}{ }^{-}, \mathrm{NO}_{3}{ }^{-}$, and $\mathrm{HSO}_{4}{ }^{-}$. For this dataset, correlation coefficients with an abso- lute value greater than 0.033 are significantly different from zero.

Negative correlations among several positive ion pairs $\left(\mathrm{NO}^{+} / \mathrm{H}^{+}, \mathrm{NO}^{+} / \mathrm{NH}_{4}{ }^{+}, \mathrm{NO}^{+} / \mathrm{C}_{3} \mathrm{H}_{4} \mathrm{O}^{+}\right.$or $\left.\mathrm{C}_{4} \mathrm{H}_{8}{ }^{+}\right)$ indicate that, as with ammonium sulfate/nitrate, these ions are linked by competitive charge-transfer and the energetically preferred ion is $\mathrm{NO}^{+}$. Other negative correlations include $\mathrm{H}^{+} / \mathrm{C}_{2} \mathrm{H}_{3}{ }^{+}$and $\mathrm{H}^{+} / \mathrm{C}_{3} \mathrm{H}_{4} \mathrm{O}^{+}$or $\mathrm{C}_{4} \mathrm{H}_{8}{ }^{+}$, but it is not clear from these alone whether the organic cations or $\mathrm{H}^{+}$are more energetically preferred. However, the positive correlations of $\mathrm{H}^{+}$and $\mathrm{NH}_{4}^{+}$ with $\mathrm{NO}_{3}{ }^{-}$combined with the negative correlation between $\mathrm{C}_{2} \mathrm{H}_{3}{ }^{+}$and $\mathrm{NO}_{3}{ }^{-}$suggest that the relative preference is $\mathrm{NO}^{+}>\mathrm{C}_{\mathrm{x}} \mathrm{H}_{\mathrm{y}} \mathrm{O}_{\mathrm{z}}^{+}>\mathrm{H}^{+}, \mathrm{NH}_{4}{ }^{+}$. The positive correlations of $\mathrm{OH}^{-}$with $\mathrm{HSO}_{4}^{-}$and $\mathrm{NO}^{+}$ along with the negative correlations of $\mathrm{OH}^{-}$with $\mathrm{H}^{+}$, $\mathrm{NO}_{2}{ }^{-}$and $\mathrm{NO}_{3}{ }^{-}$indicate that $\mathrm{OH}^{-}$and $\mathrm{HSO}_{4}{ }^{-}$are noncompetitively formed as previously noted for the sodium sulfate-ammonium nitrate system.

\section{Conclusions}

Single particle mass spectra can vary substantially from particle to particle depending on plume dynamics. This variation is systematic, not random-the signal intensities of many ions in the mass spectra are positively or negatively correlated with each other. In general, the energetically preferred ions (e.g., lowest ionization energy, highest electron affinity) are positively correlated with each other and negatively correlated with less preferred ions. When the particle ablates in a manner giving a dense plume with many collisions, the ener- 


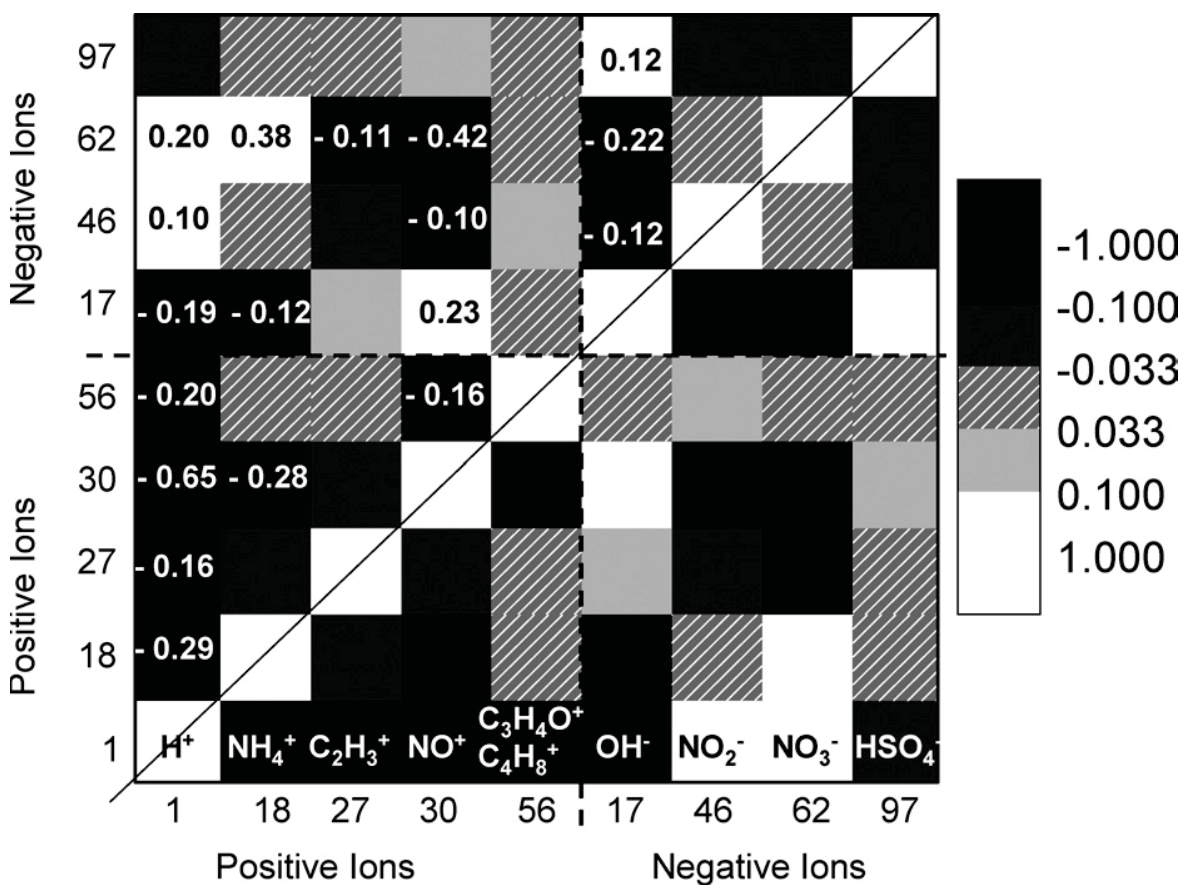

Figure 6. Covariance matrix for $220 \mathrm{~nm}$ particles generated from a solution containing a 1:1:1 mol ratio of ammonium sulfate, ammonium nitrate, and oleic acid.

getically preferred ions are dominant. When the particle ablates in a manner giving a dispersed plume with fewer collisions, the less preferred ions are able to survive and the energetically preferred ions constitute a lower fraction of the total ion signal. For sodium chloride, cluster ions $\left(\mathrm{Na}_{2} \mathrm{Cl}^{+}, \mathrm{NaCl}_{2}^{-}\right)$compete with the formation of atomic ions $\left(\mathrm{Na}^{+}, \mathrm{Cl}^{-}\right)$. For particles composed of ammonium sulfate and ammonium nitrate with or without oleic acid, $\mathrm{NO}^{+}$and $\mathrm{HSO}_{4}{ }^{-}$are the energetically preferred ions over $\mathrm{NH}_{4}{ }^{+}, \mathrm{NO}_{\mathrm{x}}{ }^{-}$, and (if present) $\mathrm{C}_{\mathrm{x}} \mathrm{H}_{\mathrm{y}} \mathrm{O}_{\mathrm{z}}{ }^{+}$. For particles composed of sodium sulfate plus ammonium nitrate, $\mathrm{Na}^{+}$and $\mathrm{HSO}_{4}{ }^{-}$are the energetically preferred ions over $\mathrm{NO}^{+}, \mathrm{NH}_{4}{ }^{+}$, and $\mathrm{NO}_{\mathrm{x}}{ }^{-}$. The results suggest that ion formation in LDI of single, isolated nanoparticles can be thought of as a two-stage process. In the first stage, ionization of laser desorbed neutrals gives cations and free electrons. In the second stage, collisions in the plume cause electron capture and/or competitive charge-transfer.

\section{Acknowledgments}

The authors acknowledge support for this research by grant number CHE-0517972 from the National Science Foundation.

\section{References}

1. Nash, D. G.; Baer, T.; Johnston, M. V. Aerosol Mass Spectrometry: An Introductory Review. Int. J. Mass Spectrom. 2006, 258, 2-12.

2. Murphy, D. M. The Design of Single Particle Laser Mass Spectrometers. Mass Spectrom. Rev. 2007, 26, 150-165.

3. Hinz, K.-P.; Spengler, B. Instrumentation, Data Evaluation, and Quantification in On-Line Aerosol Mass Spectrometry. J. Mass Spectrom. 2007, $42,843-860$.

4. Lake, D. L.; Tolocka, M. P.; Wexler, A. S.; Johnston, M. V. Mass Spectrometry of Individual Particles Between 50 and $750 \mathrm{~nm}$ in Diameter at the Baltimore Supersite. Env. Sci. Tech. 2003, 37, 3268-3274.
5. Simmons, D. S. Laser Microprobe Mass Spectrometry: Description and Selected Applications. Appl. Surf. Sci. 1988, 31, 103-117.

6. McMurry, P. H. A Review of Atmospheric Aerosol Measurements. Atmos. Environ. 2000, 34, 1959-1999.

7. McKeown, P. J.; Johnston, M. V.; Murphy, D. M. On-Line Single-Particle Analysis by Laser Desorption Mass Spectrometry. Anal. Chem. 1991, 63, 2069-2073.

8. Vera, C. C.; Trimborn, A.; Hinz, K.-P.; Spengler, B. Initial Velocity Distributions of Ions Generated by In-Flight Laser Desorption/Ionization of Individual Polystyrene Latex Microparticles as Studied by the Delayed Ion Extraction Method. Rapid Commun. Mass Spectrom. 2005, 19, 133-146.

9. Lee, D; Park, K.; Zachariah, M. R. Determination of the Size Distribution of Polydisperse Nanoparticles with Single-Particle Mass Spectrometry: The Role of Ion Kinetic Energy. Aero. Sci. Tech 2005, 39, 162-169.

10. Schoolcraft, T. A.; Constable, G. S.; Zhigilei, L. V.; Garrison, B. J Molecular Dynamics Simulation of the Laser Disintegration of Aerosol Particles. Anal. Chem. 2000, 72, 5143-5150.

11. Schoolcraft, T. A.; Constable, G. S.; Jackson, B.; Zhigilei, L. V.; Garrison, B. J. Molecular Dynamics Simulations of Laser Disintegration of Amorphous Aerosol Particles with Spatially Nonuniform Absorption. Nucl. Instrum. Methods B 2001, 180, 245-250.

12. Zhou, L.; Park, K.; Milchberg, H. M.; Zachariah, M. R. Understanding the Interaction of an Intense Laser Pulse with Nanoparticles: Application to the Quantification of Single Particle Mass Spectrometry. Aero. Sci. Tech. 2007, 41, 818-837.

13. Amoruso, S.; Bruzzese, R.; Spinelli, N.; Velotta, R. Characterization of Laser-Ablation Plasmas. J. Phys. B At. Mol. Opt. 1999, 32, R131-R172.

14. Vertes, A.; Gijbels, R.; Adams, F. E., Eds. Laser Ionization Mass Analysis; John Wiley and Sons: New York, 1993.

15. Mansoori, B. A.; Johnston, M. V.; Wexler, A. S. Quantitation of Ionic Species in Single Microdroplets by On-Line Laser Desorption/Ionization. Anal. Chem. 1994, 66, 3681-3687.

16. Tolocka, M. P.; Saul, T. D.; Johnston, M. V. Reactive Uptake of Nitric Acid into Aqueous Sodium Chloride Droplets Using Real-Time SingleParticle Mass Spectrometry. J. Phys. Chem. A 2004, 108, 2659-2665.

17. Frasinski, L. J.; Codling, K.; Hatherly, P. A. Covariance Mapping: A Correlation Method Applied to Multiphoton Multiple Ionization. Science 1989, 246, 1029-1031.

18. Berardi, V.; Spinelli, N.; R., V.; Armenante, M.; Fuso, F.; Allegrini, M.; Arimondo, E Correlation Analysis of Laser Ablated Ions from YBCO. Phys. Lett. A 1993, 179, 116-121.

19. Amoruso, S.; Berardi, V.; Spinelli, N.; Velotta, R.; Armenante, M.; Fuso, F.; Allegrini, M.; Arimondo, E. Time of Flight Mass Spectrometry and Covariance Mapping Technique Investigation of Charged Specie Evolution in $\mathrm{Pb}(\mathrm{Ti0} .48 \mathrm{Zr0}$.52)O3 Laser Ablation. Science 1995, 86, 35-39.

20. Wang, X.; Amoruso, S.; Tortora, A.; Armenante, M.; Bruzzese, R.; Velotta, R.; Spinelli, N. Analysis of Charged Fragments Emitted During Excimer Laser Ablation of YNi2B2C Borocarbide Targets by Time-ofFlight Mass Spectrometry. Appl. Surf. Sci. 2002, 186, 303-308. 
21. Card, D. A.; Folmer, D. E.; Sato, S.; Buzza, S. A.; Castleman, J.; A. W. Covariance Mapping of Ammonia Clusters: Evidence of the Connectiveness of Clusters with Coulombic Explosion. J. Phys. Chem. A 1997, 101, 3417-3423.

22. Foltin, M.; Stueber, G. J.; Bernstein, E. R. Dynamics of Neutral Cluster Growth and Cluster Ion Fragmentation for Toluene/Water, Aniline/ Argon, and 4-Fluorostyrene/Argon Clusters: Covariance Mapping of the Mass Spectral Data. J. Chem. Phys. 1998, 109, 4342-4360.

23. Feldman, A. B.; Antoine, M.; Lin, J. S.; Demirev, P. A. Covariance Mapping in Matrix-Assisted Laser Desorption/Ionization Time-of-Flight Mass Spectrometry. Rapid Commun. Mass Spectrom. 2003, 17, 991-995.

24. Sigman, M. E.; Williams, M. R. Covariance Mapping in the Analysis of Ignitable Liquids by Gas Chromatography/Mass Spectrometry. Anal. Chem. 2006, 78, 1713-1718.

25. Sigman, M. E.; Williams, M. R.; Ivy, R. G. Individualization of Gasoline Samples by Covariance Mapping and Gas Chromatography/Mass Spectrometry. Anal. Chem. 2007, 79, 3462-3468.

26. Phares, D. J. Rhoads, K. P. Wexler, A. S. Kane, D. B. Johnston, M. V. Application of the ART-2a algorithm to Laser Ablation Aerosol Mass Spectrometry of Particle Standards. Anal. Chem. 2001, 73, 2338-2344.

27. Tolocka, M. P.; Lake, D. L.; Johnston, M. V.; Wexler, A. S. Size-Resolved Fine and Ultrafine Particle Composition in Baltimore, MD. J. Geophys. Res. Atmos 2005, 110, D07S04.

28. Reinard, M. S., Adou, K., Martini, J. M., Johnston, M. V. Source Characterization and Identification by Real-Time Single Particle Mass Spectrometry. Atmos. Environ. 2007, in press.

29. Phares, D. J.; Rhoads, K. P.; Wexler, A. S. Performance of a Single Ultrafine Particle Mass Spectrometer. Aero. Sci. Tech. 2002, 36, 583-592.

30. Frankevich, V. E.; Zhang, J.; Friess, S. D.; Dashtiev, M.; Zenobi, R. Role of Electrons in Laser Desorption/Ionization Mass Spectrometry. Anal. Chem. 2003, 75, 6063-6067.
31. Carson, P. G.; Johnston, M. V.; Wexler, A. S. Real-Time Monitoring of the Surface and Total Composition of Aerosol Particles. Aero. Sci. Tech. 1997, 26, 291-300.

32. Zenobi, R.; Knochenmuss, R. Ion Formation in MALDI Mass Spectrometry. Mass Spectrom. Rev. 1998, 17, 337-366.

33. Harris, W. A.; Reilly, P. T. A.; Whitten, W. B. MALDI of Individua Biomolecule-Containing Airborne Particles in an Ion Trap Mass Spectrometer. Anal. Chem. 2005, 77, 4042-4050.

34. Carson, P. G.; Johnston, M. V.; Wexler, A. S. Laser Desorption/ Ionization of Ultrafine Aerosol Particles. Rapid Commun. Mass Spectrom. 1997, 11, 993-996.

35. Kane, D. B.; Wang, J.; Frost, K.; Johnston, M. V. Detection of Negative Ions from Individual Ultrafine Particles. Anal. Chem. 2002, 74, 2029 2069.

36. Lake, D. L.; Tolocka, M. P.; Johnston, M. V.; Wexler, A. S. The Character of Single Particle Sulfate in Baltimore. Atmos. Environ. 2004, 38, 53115320 .

37. Bein, K. J.; Zhao, Y.; Pekney, N. J.; Davidson, C. I.; Johnston, M. V.; Wexler, A. S. Identification of Sources of Atmospheric PM at the Pittsburgh Supersite, Part II: Quantitative Comparisons of Single Particle, Particle Number, and Particle Mass Measurements. Atmos. Environ. 2005, 40, 424-444.

38. Rohlf, F. J.; Sokal, R. R., Eds. Statstical Tables, 2nd ed.; W. H. Freeman and Company: San Francisco, 1981; p 166.

39. Reilly, P. T. A.; Lazar, A. C.; Gieray, R. A.; Whitten, W. B.; Ramsey, J. M. The Elucidation of Charge-Transfer-Induced Matrix Effects in Environmental Aerosols Via Real-Time Aerosol Mass Spectral Analysis of Individual Airborne Particles. Aero. Sci. Tech. 2000, 33, 135-152.

40. Arnold, F.; Viggiano, A. A.; Schlager, H. Implications for Trace Gases and Aerosols of Large Negative Ion Clusters in the Stratosphere. Nature $1982,297,371-376$. 